\title{
Ortaöğretim Türk Edebiyatı Program ve Ders Kitaplarının Somut Olmayan Kültürel Miras Ögeleri Açısından İncelenmesi
}

\author{
Examination of Secondary School Turkish Literature Curriculum and \\ Textbooks in Terms of Intangible Cultural Heritage Items
}

DOI=10.17556/jef.11705

Vafa ŞAVAŞKAN

Özet

Günümüzde geçerliliğini sürdüren küreselleşme olgusunun, yarattığı kitle kültürü ile somut olmayan kültürel miras olarak adlandırılan, topluluklar tarafindan kuşaktan kuşağa aktarılan uygulamaların, temsillerin, ifadelerin, bilginin ve becerilerin kaybolmasına neden olan olumsuz yönlere sahip olduğu bir gerçektir. Eğitim süreciyle arasında karşılıklı ve işlevsel bir ilişkinin söz konusu olduğu kültür, her toplumsal değer gibi sürekli değişken bir yapıya sahiptir. Kültürel mirasın diğer nesillere aktarılmadığı, geleceğe taşınmadığı takdirde aidiyet ve devamlılık duygusunun da kaybolması veya önemini yitirmesi olağan bir durumdur. Bu nedenle, Türk Edebiyatı Öğretim Programı'nda ve Türk edebiyatı ders kitaplarında Türk kültürüne ait olan somut olmayan kültürel mirasın yeterli şekilde aktarılmasının gerekliliği önem arz etmektedir.

Bu araştırmanın amacı, somut olmayan kültürel mirası koruma bakımından 9, 10, 11 ve 12. sınıf Türk Edebiyatı Öğretim Programı ve ders kitaplarının üstlendikleri görevi yerine getirip getirmediğinin belirlenmesidir. Bu amaç doğrultusunda Türk Edebiyatı Öğretim Programı'ndaki kazanımlarda, etkinlik örneklerinde ve açıklamalarda; Türk Edebiyatı ders kitaplarında yer alan metinlerde Somut Olmayan Kültürel Mirasın Korunması Sözleşmesine göre halk bilimi kadroları ile ilgili ögeler (yaşayan insan hazineleri / geleneğin ustaları; sözlü gelenekler ve anlatımlar; gösteri sanatları; toplumsal uygulamalar, ritüeller ve şölenler; el sanatları geleneği; doğa ve evrenle ilgili uygulamalar) incelenmiştir.

Anahtar Sözcük: edebiyat eğitimi, Türk edebiyatı ders kitapları, Türk edebiyatı öğretim programı, somut olmayan kültürel miras.

\footnotetext{
Abstract

Globalization, which is still dominant in today's world, causes the disappearance of applications, representations, expressions, information and skills that are transmitted across cohorts and called intangible cultural heritage via the mass culture. Culture, which has a mutual and functional relationship with education, changes all the time as all the other values in society. It is highly possible that the sense of
} 
belonging and continuity would disappear when the cultural heritage is not transmitted to future generations.

Thus, Turkish Literature Teaching Curriculum and Turkish Literature textbooks should include items facilitating the transmission of the intangible cultural heritage of Turkish culture. The aim of the present study is to examine whether 9th, 10th, 11th, and 12th grade Turkish Literature Teaching Curriculum and the textbooks help the transmission of the intangible cultural heritage. To achieve this aim, related items (living human treasures / masters of the tradition; oral traditions and expressions, performing arts; social practices, rituals and festivals; crafts; practices concerning the nature and universe) of folklore based on the Intangible Cultural Heritage Aggreement in the objectives of Turkish Literature Curriculum, activities and explanations, and texts in Turkish Literature textbooks were investigated.

Keywords: literature education, Turkish literature textbooks, Turkish literature curriculum, intangible cultural heritage.

\section{Giriş}

En genel anlamıyla kültürün bir parçası olarak düşünülebilen (Emre, 2012, 148), Bat1 dillerine Latince "harflerden meydana getirilmiş şey" anlamına gelen "literature" kelimesinden geçen "edebiyat" sözcüğü, Türkçede daha çok "kültürel birikim" ve "belli bir bilimsel alanda ortaya konan eserler bütünü" gibi anlamlarda kullanılmaktadır (Doğan, 1990, 229)

Türk Dil Kurumu'un yayınladığı Türkçe Sözlük’te “1.Olay, düşünce, duygu ve hayallerin dil aracılığıyla sözlü veya yazılı olarak biçimlendirilmesi sanatı, yazın (II), gökçe yazın. 2. Bir bilim kolunun türlü konuları üzerine yazılmış yazı ve eserlerin hepsi, literatür" (TDK, 2005, 600) olarak tanımlanan edebiyat, zevk alınması gereken bir sanat alanı olmanın yanı sıra eğitim ve kültürlenme aracı olarak da kullanılmaktadır (Solak, 2014, 89).

Edebiyatı kültürün bir parçası olarak nitelendirmenin ardından, kültürün de edebi eserin içinde taşınan, topluma özgü bir değer olduğunu söylemek yerinde olacaktır. Var olma sürecinde edebiyat, kültürden yararlanırken, kültür de kendini bir durumdan ötekine edebiyat aracılığıyla taşımaktadır (Emre, 2012, 148).

Eğitim süreciyle arasında karşılıklı ve işlevsel bir ilişkinin söz konusu olduğu kültür, her toplumsal değer gibi sürekli değişken bir yapıya sahiptir. Kültürel mirasın diğer nesillere aktarılmadığg, geleceğe taşınmadığı takdirde aidiyet ve devamlılık duygusunun da kaybol- 
ması veya önemini yitirmesi olağan bir durumdur. Bu nedenle, Türk Edebiyatı Öğretim Programında ve Türk edebiyatı ders kitaplarında Türk kültürüne ait olan somut olmayan kültürel mirasın yeterli şekilde aktarılmasının gerekliliği önem arz etmektedir.

Bilindiği üzere, edebiyatın kültürün bir parçası olduğu ve edebiyat derslerinin kültürel değerleri aktarmada önemli rol oynamasının kaçınılmaz gerçek olduğu savları üzerine eskiden beri konuşulmaktadır. Var olan ve sürekli dile getirilen bu söylemlerin yanında ana dilimizin ve ulusal kültürümüzün öğretilmesine özen göstermemiz ve sahip çıkmamız gerektiği düşüncesi de yadsınamaz bir gerçek olarak karşımıza çıkmaktadır. Bir toplumun dilini, edebiyatını, yaşayıș biçimini, zevklerini, folklorunu, sanatsal etkinliklerini vb. içeren ögenin milli kültür olduğu bilinmektedir. Milli kültürün en başta gelen ögelerinden birinin dil, diğerinin edebiyat olduğu dikkate alındığında özellikle liselerde Türk dili ve edebiyatı öğretimini gerçekleştirenlere büyük görev düşmektedir.

Elbette ki eğitim sisteminin kalitesini tek başına öğretmen belirlemez. En az öğretmen kadar önemli olan bir nokta da ders programıdır. $\mathrm{Bu}$ sebeple eğitim sisteminin verimliliğinin artmasında nitelikli öğretmen ve ihtiyaçlara cevap veren bir program vazgeçilmez iki unsur durumundadir (Y1lmaz, 2014, 187).

Edebiyat derslerinde diğer önemli unsur ise edebî metinlerdir. Edebiyatla ilgili zevk, anlayış ve becerilerin okul veya okul dışı araştırma etkinliklerinin edebî metinlerden hareketle düzenleneceği bilinmektedir. Ders kitaplarına metin seçiminde bugüne kadar yazarlar esas alınmış ve onların adları programda belirtilmiştir; oysa bu program, metni esas almaktadır (MEB, 2011, 12).

Örgün anlamda okulda öğrenilen dil ve edebiyat derslerinin kültürün gelişmesiyle sıkı sıkıya bağlantılı olduğu bir gerçektir. $\mathrm{Bu}$ nedenle, edebiyat derslerinde kullanılan edebi eserlerin yalın türden bir nesne olmadığı bilinmeli ve dersler, cağdan cağa suren etkisi, toplumbilimsel, tarihsel, kültürel boyutlar da taşıdığı gerçeği göz ardı edilmeden işlenmelidir

Günümüzde geçerliliğini sürdüren küreselleşme olgusunun, yarattığı kitle kültürü ile somut olmayan kültürel miras olarak adlandırılan, topluluklar tarafindan kuşaktan kuşağa aktarılan uygulamaların, temsillerin, ifadelerin, bilginin ve becerilerin kaybolmasına 
neden olan olumsuz yönlere sahip olduğu bir gerçektir. Eğitim süreciyle arasında karşılıklı ve işlevsel bir ilişkinin söz konusu olduğu kültür, her toplumsal değer gibi sürekli değişken bir yapıya sahiptir. Kültürel mirasın diğer nesillere aktarılmadığı, geleceğe taşınmadığı takdirde aidiyet ve devamlılık duygusunun da kaybolması veya önemini yitirmesi olağan bir durumdur. Bu nedenle, Türk Edebiyat1 Öğretim Programı'nda ve Türk edebiyatı ders kitaplarında Türk kültürüne ait olan somut olmayan kültürel mirasın yeterli şekilde aktarılmasının gerekliliği önem arz etmektedir.

"Somut olmayan kültürel miras" terimi, "somut kültürel miras" çalışmalarının doğal bir sonucu olarak kısa adı ile UNESCO'nun "kültür varlıklarının korunması" için yürüttüğü programlar sırasında doğmuştur (Oğuz, 2013, 59).

$\mathrm{Bu}$ araştırmada da asıl kavram olarak yer alan "somut olmayan kültürel miras" teriminin ortaya çıkışının Türkiye'nin de içinde bulunduğu 20 ülke tarafindan 1946 yılında kurulan UNESCO'nun 70 yıla yaklaşan tarihi kadar uzun bir "arayış dönemi" ve öyküsü vardır (Oğuz, 2013: 59).

Somut olmayan kültürel mirasin ne olduğu, Somut Olmayan Kültürel Mirasın (SOKÜM) Korunması Sözleşmesi ile ortaya koyulmuştur. Bu Sözleşme, bir toplumun kendi kültürel kimliğinin bir parçası olarak gördügü ve kuşaktan kuşağa aktarmak suretiyle günümüze kadar getirdiği somut olmayan kültürel miraslarını korumasına ve gelecek kuşaklara aktarmasına katkı sağlayacak yol, yöntem ve imkânları tanımlamaktadır (Oğuz, 2009, 8). Sözleşmenin korumayı amaçladığı somut olmayan kültürel miras alanları, "Somut olmayan kültürel mirasın aktarılmasında taşıyıcı işlevi gören dille birlikte sözlü gelenekler ve anlatımlar, gösteri sanatlar, toplumsal uygulamalar, ritüeller ve şölenler, doğa ve evrenle ilgili bilgi ve uygulamalar, el sanatlarl gelene ği" başlıklarında sıralanabilir (Oğuz, 2013, 64).

UNESCO, gerek sözleşmede gerekse sonraki çalışmalarla açıklık kazanan yaklaşımlarıyla, somut olmayan kültürel mirası, öncelikle bu mirası yaratan ve koruyan toplumun sonra da bütün insanlığın ortak belleği olarak görmektedir (Oğuz, 2013, 65). Bu düşüncelere 1şık tutmak adına, Türkiye gerek hazırlık döneminde gerekse yürürlüğe girmesinden sonra güçlü destek vermiş ve vermeye devam etmektedir. Türkiye'nin bu sözleşmeye bu denli önem vermesinin nedenlerini Oğuz (2013) şu şekilde açıklamaktadır: Türkiye, insanlığın yer- 
leşme, hayvansal ve tarımsal üretim yapma tarihinin önemli bir bölümünün gerçekleştiği topraklar üzerindedir. Bu nedenle, Türkiye insanlığın on-on beş bin yıl veya daha fazla bir yerleşme öyküsünün önemli adreslerinden biri olmuştur. Türkiye' de bulunması gereken, korunması gereken sayısız insanlık mirası toprak altında yatmakta ve yeni çalışmalar yapılmasını beklemektedir. Diğer yandan Türkiye topraklarında geçmişi 2-3 bin yıl önceye dayanan tarihsel yapılar ve sit alanları, son bin y1llı Türk- İslam eserleriyle yan yana Türkiye'nin "somut" kültürel zenginlikleri olarak varlıklarını sürdürmektedirler. Bu zengin birikimi oluşturan, koruyan, yaşatan, yeniden üreten veya bunların yanlarına yenilerini katan coğrafyanın "somut olmayan" kültürel mirasının da korunmaya, araştırılmaya, gelecek kuşaklara aktarılmaya ve yeniden üretilmeye değer olduğu aşikârdır.

Somut Olmayan Kültürel Mirasın neden ve nasıl korunması gerektiğinin biçimlendiren Sözleşmenin (SOKÜM) amaçlarının gerçekleşmesi bakımından üzerinde durulan ve önem verilen konulardan birisi de toplumsal bilincin yükseltilmesi, eğitim süreçlerinde somut olmayan mirasın korunmasına yönelik duyarlılığın güçlendirilmesi konusudur. Sözleşmenin "Eğitim, Duyarlığın ve Kapasitenin Güçlendirilmesi" başlıklı 14. maddesi bu konuyu şu şekilde açıklamaktadır: (i)Toplumun genelini ve özellikle gençleri hedefleyen eğitici, duyarl-lı̆̆l arttırıcı ve bilgilendirici programlar düzenlemek; (ii) İlgili topluluklar ve gruplar içinde belirli eğitim ve yetiştirme programları düzenlemek; (iii) somut olamayan kültürel mirasın korunması için özellikle yönetim ve bilimsel araştırma gibi alanlarda kapasite güçlendirici etkinlikler düzenlemek"

Ekici (2004), somut olmayan kültürel mirasın korunmasının, bu mirasın "sürdürülebilir" kılınmasıyla mümkün olacağını söyler. Bunun için de somut olmayan kültürel mirasın öneminin genç kuşaklara anlatılması gerekmektedir. Genç neslin, günümüzde somut olmayan kültürel mirasın yenilemez bir değerde olduğunun fakında olması, bu mirasın korunmasında ve yaşatılmasında önemli rol oynayacaktır. $\mathrm{Bu}$ nedenle eğitim sistemlerinin gençlere, kültürel miraslarının önemini göstermeleri ve kültürel mirası korumak için farkındalık oluşturmaları gerekmektedir (Renault, 2008, 13, 40; Akt. Yeşilbursa, 2011, 34).

$\mathrm{Bu}$ noktada, kültürün sonraki kuşaklara aktarılmasında eğitimin önemli bir rolü olduğunun ve okullardaki eğitim ve öğretimin esas görevinin kültürün kuşaklara aktarılması ve sürdürüleblirliğinin 
sağlanması olduğu unutulmamalıdır. Kültürel miras eğitimine doğrudan hizmet veren halk kültürü dersinin yanı sıra Türkiye'de örgün eğitim sürecinde ilkokul, ortaokul ve lise düzeyinde kültürel miras eğitimi en fazla Sosyal Bilgiler, Türk Dili ve Edebiyatı, Türkçe ve Tarih derslerinde verilmektedir (Akhan, 2014, 726)

Buradan yola çıkarak bu çalışmanın temel amacını, 9, 10, 11 ve 12. sınıf Türk Edebiyatı Öğretim Programı'nda yer alan kazanımlarda, etkinlik örneklerinde ve açıklamalarda ve Türk Edebiyatı ders kitaplarında $(9,10,11,12)$ yer alan metinlerde SOKÜM sözleşmesine göre halk bilimi kadroları ile ilgili ögeler (yaşayan insan hazineleri / geleneğin ustaları; sözlü gelenekler ve anlatımlar; gösteri sanatları; toplumsal uygulamalar, ritüeller ve şölenler; el sanatları geleneği) incelenmesi oluşturmaktadır.

\section{Araştırmanın Amacı}

$\mathrm{Bu}$ araştırmanın amacı, somut olmayan kültürel mirası koruma bakımından Türk Edebiyatı Öğretim Programı $(9,10,11,12)$ ve Türk edebiyatı $(9,10,11,12)$ ders kitaplarının üstlendikleri görevi yerine getirip getirmediğinin belirlenmesidir. $\mathrm{Bu}$ amaç doğrultusunda Türk Edebiyatı Öğretim Programı'nda $(9,10,11,12)$ yer alan kazanımlarda, etkinlik örneklerinde ve açıklamalar kısmında; Türk edebiyatı ders kitaplarında $(9,10,11,12)$ yer alan metinlerde somut olmayan kültürel miras alanları ile ilgili ögeler (yaşayan insan hazineleri / geleneğin ustaları; sözlü gelenekler ve anlatımlar; gösteri sanatları; toplumsal uygulamalar, ritüeller ve şölenler; el sanatları geleneği) incelenmiştir.

\section{Yöntem}

\section{Araştırmanın Modeli}

Somut olmayan kültürel mirası koruma bakımından Türk Edebiyatı Öğretim Programı $(9,10,11,12)$ ve Türk edebiyatı $(9,10$, $11,12)$ ders kitaplarının üstlendikleri görevi yerine getirip getirmediğini belirlemeye çalışan bu araştırma, nitel bir araştırma olup doküman incelemesi yoluyla değerlendirilmiştir. Nitel araştırmalarda gözlem, görüşme ve doküman analizi gibi nitel veri toplama yöntem- 
leri kullanılır ve algılar ile olaylar doğal ortamda gerçekçi ve bütüncül bir biçimde ortaya konmaya çalışılır (Yı1dırım ve Şimşek, 2005).

Doküman incelemesi yaparken izlenebilecek birçok aşama vardır. Her araştırmacı bu aşamaları yeniden yorumlayabilir. $\mathrm{Bu}$, araştırmacının doküman incelemesi sonucunda elde etmeyi hedeflediği veriyi veya dokümanları ne kadar kapsamlı ve derinlemesine incelemek istediğine ve araştırma probleminin niteliğine bağlı olarak gelişmektedir (Yıldırım, Şimşek, 2001, 193). Bu araştırmada, araştırmanın kuramsal temellerini ortaya koymak amacıyla öncelikle somut olmayan kültürel miras konusunda bir alan yazın taraması yapılmıştır. Daha sonra bu kapsamda Türk Edebiyatı Öğretim Programı $(9,10,11,12)$ ve Türk edebiyatı $(9,10,11,12)$ ders kitapları incelenmiş, elde edilen veriler değerlendirilmiştir.

Araştırmada Türk edebiyatı öğretim programında yer alan kazanımlar, etkinlik örnekleri ve açıklamalarla Türk Edebiyatı ders kitaplarındaki $(9,10,11,12)$ metinler tek tek incelenerek elde edilen bulgular frekanslarla tablolar hâlinde sunulmuştur. Araştırmada incelenen verilerden gerektiğinde doğrudan alıntılar yapılmıştır.

\section{Evren ve Örneklem}

$\mathrm{Bu}$ araştırmanın evrenini, Türk Edebiyatı Ö̆gretim Programı (9, $10,11,12)$ ve Türk Edebiyatı $(9,10,11,12)$ ders kitapları oluşturmaktadır. Araştırmada ayrıca bir örnekleme yapılmamış, evrenin tamamı değerlendirilmiştir.

\section{Veri Toplama Teknikleri}

Araştırmada, alan yazından yararlanılarak ve alan uzmanı görüşü alınarak somut olmayan kültürel mirası koruma bakımından Türk Edebiyatı Öğretim Programı $(9,10,11,12)$ ve Türk Edebiyatı (9, $10,11,12)$ ders kitaplarının üstlendikleri görevi yerine getirip getirmediğini belirlenmeye çalışılmıştır.

Araştırmanın güvenirlik hesaplaması için Miles ve Huberman’ın (1994) önerdiği güvenirlik formülü kullanılmıştır. 
Şekil 1: Miles ve Huberman'1n Önerdiği Güvenirlik Formülü

$$
\mathrm{R}(\text { Güvenirlik })=\frac{\mathrm{Na}(\text { Görüş Birliği })}{\mathrm{Na}(\text { Görüş Birliği })+\mathrm{Nd}(\text { Görüş Ayrılığı) }}
$$

Araştırmanın güvenirlik çalışması için bir başka uzmandan incelenen Türk Edebiyatı Öğretim Programı'nda $(9,10,11,12)$ yer alan kazanımlar, etkinlik örnekleri ve açıklamalarla Türk edebiyatı ders kitaplarındaki $(9,10,11,12)$ metinlerin somut olmayan kültürel miras bakımından değerlendirmesi istenmiştir. Veriler değerlendirilirken belirlenen örneklerin somut olmayan kültürel miras alanları ile (yaşayan insan hazineleri / geleneğin ustaları; sözlü gelenekler ve anlatımlar; gösteri sanatları; toplumsal uygulamalar, ritüeller ve şölenler; doğa ve evrenle ilgili uygulamalar; el sanatları geleneği) ilgili olmasına hem araştırmacı hem de alan uzmanı dikkat etmişlerdir. İncelenen kazanım ve etkinlik örnekleriyle metinlerde somut olmayan kültürel miras alanlarıyla ilgili en az bir ögenin olması temel ölçüt olarak kabul edilmiştir. Araştırmacı ve alan uzmanı görüş birliğine vardıkları zaman güvenirlik sürecinin son bulduğuna karar verilmiştir. Sonraki aşamada yapılan çalışmalar karşılaştırılarak güvenirlik hesaplaması gerçekleştirilmiştir. Hesaplamanın sonunda $\mathrm{p}=0,82$ değeri bulunmuştur. Güvenirlik hesaplarının \% 70'in üzerinde çıkması, araştırma için güvenilir kabul edilmektedir (Miles ve Huberman, 1994). Buna dayanarak elde edilen sonuç, araştırma için güvenilir kabul edilmiştir. Güvenirlik sürecinden geçerek elde edilen bulgular, frekanslarla tablolar hâlinde sunulmuş, gerektiğinde doğrudan alıntılara yer verilmiştir.

\section{Bulgular}

$\mathrm{Bu}$ bölümde, araştırma kapsamında incelenen Türk Edebiyatı Öğretim Programı'nda $(9,10,11,12)$ yer alan 649 kazanım, 269 etkinlik örneği, 322 açıklama ile Türk Edebiyatı ders kitaplarında yer alan 401 metinden elde edilen bulgular, araştırma amaçlarındaki sıraya uygun olarak alt başlıklar biçiminde sunulmuştur. Tablolarda Türk Edebiyatı Öğretim Programı $(9,10,11,12)$ ve Türk edebiyatı $(9$, 
$10,11,12)$ ders kitaplarında yer alan somut olmayan kültürel mirasa ilişkin örnekler sayı ve oran olarak verilmiş, gerektiğinde bu örneklerden doğrudan alıntılar yapılarak örneklendirilmeye gidilmiştir.

Türk Edebiyatı Ö̆̆retim Programına (9, 10, 11, 12) Yönelik

Bulgular

Türk Edebiyatı Öğretim Programının $(9,10,11,12)$ incelenmesi aşamasında "kültürel değerler"in genel bir kavram olarak kullanıldığı gözlemlenmiştir. Programlarda yer alan kazanımlarda ve etkinlik örneklerinde kültürel değerlerin işlevlerinden bahsederek korunması gerektiği vurguları yapılmıştır.

Değerlendirmeye alınan Türk Edebiyatı Öğretim Programı'nda $(9,10,11,12)$ yer alan kazanım ve etkinlik örneklerine ilişkin sayısal bilgiler şu şekildedir:

Tablo 1. Değerlendirilen Türk Edebiyatı Öğretim Programı'ndaki (9, 10, 11, 12) "Kültür” Kavramına Yönelik Vurgular İçeren Kazanımların Sınıf Düzeylerine Göre Dağılımı.

\begin{tabular}{cccc}
\hline Sınıflar & $\begin{array}{c}\text { Sınıf Düzeylerine Göre } \\
\text { Toplam Kazanım (f) }\end{array}$ & \multicolumn{2}{c}{$\begin{array}{c}\text { Somut Olmayan Kültürel Mirasa íliş- } \\
\text { kin Kazanım Sayıları ve Oranları }\end{array}$} \\
\cline { 3 - 4 } 9. Sınıf & 123 & $(\mathrm{f})$ & $\%$ \\
10. Sınıf & 152 & 4 & 4,92 \\
11. Sınıf & 199 & 9 & 13,68 \\
12. Sınıf & 175 & 6 & 11,94 \\
TOPLAM & 649 & 2 & 3,5 \\
\hline
\end{tabular}

Tablo 1'de görüldüğü üzere incelemeye tabi tutulan Türk Edebiyatı Öğretim Programı'nda $(9,10,11,12)$ yer alan toplam 649 kazanımdan 123'ü 9. sinıfa; 152'si 10. sinıfa; 199'u 11. sinıfa; 175'i ise 12. sinıfa aittir. 9. sinıfa ait 123 kazanımdan \%4,92'si (f 4); 10. sinıfa ait 152 kazanımdan \%13,68'i (f 9); 11. sinıfa ait 199 kazanımdan \%11,94'ü (f 6); 12. sinıfa ait 175 kazanımdan \%3,5'i (f 2) "kültür" kavramına yönelik vurgular içermektedir.

Türk Edebiyatı Öğretim Programı'nın $(9,10,11,12)$ “Kazanımlar" kısmında yer alan "kültür" kavramıyla ilgili vurgulardan bazıları şunlardır: 
"Aynı dili konuşan insan topluluklarının ortak kültür değerlerini paylaştıklarını açıklayan örnekler verir." (9. sınıf s. 19)

"Dilin kültür taşıyıcısı rolünü belirler." (9. sınıf s. 19)

"Dilin, kültür alanının oluşumundaki rolü ve değerini örneklerle açıklar." (9. sınıf s. 19) sinif s. 25)

"Sosyal ve kültürel ortamın şiir geleneğine etkisini açılar." (9.

"Destanın, dönemin tarihî, siyasi ve kültürel yapısıyla ilişkisini sorgular." (10. sinif s. 45)

"İslamiyet'in kabulüyle Türklerin sosyal, siyasi ve kültürel hayatındaki değişimi açıklar." (10. sınıf s. 47)

"İslami Dönem ilk dil ve edebiyat ürünlerinin edebiyat ve kültür tarihimizdeki yeri ve değerini açıklar." (10. sınıf s. 48)

"İslami Dönem ilk dil ve edebiyat ürünlerindeki kültürel farklılaşmayı örneklerle açıklar." (10. sınıf s. 48)

"İslami Dönem ilk dil ve edebiyat metinlerinin dil, söyleyiş ve kültür özelliklerini açıklar." (10. sınıf s. 48)

"İslamiyet'in kabulüyle Türk toplumunda görülen kültür farklılığını açıklar.” (10. sınıf s. 49)

"İncelediği metinden hareketle metnin sade ve sanatkârane oluşunun arkasında bir kültür ve zevk farklılığının olduğunu açıklar." (10. sinif s. 60)

"Tanzimat öncesi zihniyet ile Tanzimat sonras1 zihniyeti ve kültür değerlerini karşılaştırır." (11. sınıf s. 60)

"Gazetenin öğretici metinler başta olmak üzere kültür ve edebiyatımızda yüklendiği işlevlerini belirler." (11. sınıf s. 64)

"Tanzimat Dönemi Edebiyatını etkileyen sosyal, siyasal ve kültürel ortamın özelliklerini açıklar." (11. sınıf s. 70)

"Tiyatro eserlerinin kültür değişmesini yansitıp yansıtmayacağını sorgular." (12. sınıf s. 114)

Tablo 2: Değerlendirilen Türk Edebiyatı Öğretim Programı'ndaki $(9,10,11,12)$ "Kültür" Kavramına Yönelik Vurgular İçeren Etkinlik Örneklerinin Sınıf Düzeylerine Göre Dağılımı 


\begin{tabular}{cccc}
\hline Sinıflar & $\begin{array}{c}\text { Sınıf Düzeylerine Göre } \\
\text { Toplam Etkinlik Örnekle- } \\
\text { ri (f) }\end{array}$ & $\begin{array}{c}\text { Somut Olmayan Kültürel Mirasa iliş- } \\
\text { kin Etkinlik Örneklerinin Sayıları ve } \\
\text { Oranları }\end{array}$ \\
\cline { 3 - 4 } 9. Sınıf & 70 & $(\mathrm{f})$ & $\%$ \\
10. Sınıf & 70 & 3 & 2,1 \\
11. Sınıf & 79 & 3 & 2,1 \\
12. Sınıf & 50 & 2 & 1,58 \\
TOPLAM & 269 & - & - \\
\hline
\end{tabular}

Tablo 2'de görüldüğü gibi incelemeye tabi tutulan Türk Edebiyatı Öğretim Programı'nda $(9,10,11,12)$ yer alan toplam 269 etkinlik örneğinden 70'i 9. sınıfa; 70'i 10. sınıfa; 79'u 11. sınıfa; 50'si ise 12. sınıfa aittir. 9. sınıfa ait 70 etkinlik örneğinden $\% 2,1$ 'i (f 3); 10. sınıfa ait 70 etkinlik örneğinden $\% 2,1$ 'i (f 3); 11. sinıfa ait 79 etkinlik örneğinden \%1,58'i (f 2 ) "kültür" kavramına yönelik vurgular içermektedir. İncelenen 12. sınıfa ait 50 etkinlik örneğinde ise "kültür" kavramına yönelik herhangi bir vurgu saptanmamıştır.

Türk Edebiyatı Öğretim Programı'nın $(9,10,11,12)$ "Etkinlik Örnekleri" kısmında yer alan "kültür" kavramıyla ilgili vurgulardan bazıları şunlardır:

"Öğrenciler gruplar hâlinde dilin kültür taşıyıcısı rolünün önemini ve değerini tartışırlar. Her grubun sözcüsü tartışma sonucunu sınıfa sunar. Ortak maddelerden sınıfça bir poster oluşturulur, sınıfın duvarına asılır." (9. sinıf s. 19)

"Gruplara ayrılmış öğrencilerin dönemin zihniyeti, sanat anlayış1, sosyal ve kültür hayatına ait özellikleri tartışarak maddeler hâlinde yazmaları istenir." (9. sinıf s. 23)

"Öğrenciler gruplara ayrılır. Her grup, önce ders kitabına alınmış zihniyetle ilgili parçalarda sosyal ve siyasi hususları ifade eden kelime, kelime grubu ve cümleleri belirler; sonra da aynı metinlerde kültürle ilgili hususları saptar. Bunlardan hareketle dönemin sosyal, siyasal ve kültürel durumu hakkında çıkarımlarda bulunur." (9. sinif s. 36).

"Metinler; yapı, tema, dil ve anlatım, hitabet özellikleri, tarihî ve kültürel önemleri, yazılış amaçları, kim tarafından kime, hangi şartlarda yazıldığı yönlerinden karşılaştırırlar.” (10. sınıf s. 46) 
“Öğrenci grupları, İslamiyet'in kabulüyle Türklerin sosyal, siyasi, kültür ve dil alanlarında gerçekleştirdikleri değişiklikleri belirler." (10. Sinif s. 47)

Öğrenciler, gazete çevresinde kültür ve edebiyat hayatımıza giren öğretici metin türlerini araştırırlar.” (11. sınıf s. 64)

"Öğrenciler, Fecr-i Âtî topluluğunun oluşmasını hazırlayan sosyal, siyasi ve kültürel sebepler olup olmadığını araştırırlar." (11. sinif s. 79)

Tablo 3: Değerlendirilen Türk Edebiyatı Öğretim Programı'ndaki $(9,10,11,12)$ "Kültür” Kavramına Yönelik Vurgular İçeren Açıklamaların Sınıf Düzeylerine Göre Dağılımı.

\begin{tabular}{cccc}
\hline & & \multicolumn{2}{c}{$\begin{array}{c}\text { Somut Olmayan Kültürel Mirasa iliş- } \\
\text { kin Açılama Sayıları ve Oranları }\end{array}$} \\
\cline { 3 - 4 } Sinıflar & $\begin{array}{c}\text { Sınıf Düzeylerine Göre } \\
\text { Toplam Açıklama (f) }\end{array}$ & $(\mathrm{f})$ & $\%$ \\
9. Sınıf & 62 & 10 & 6,2 \\
10. Sinıf & 77 & 4 & 3,08 \\
11. Sinıf & 98 & 4 & 3,92 \\
12. Sinıf & 85 & - & - \\
TOPLAM & 322 & 18 & 57,96 \\
\hline
\end{tabular}

Tablo 3'ten anlaşıldı̆̆ gibi incelemeye tabi tutulan Türk Edebiyatı Öğretim Programı'nda $(9,10,11,12)$ yer alan toplam 322 açıklamadan 62'si 9. sınıfa; 77'si 10. sınıfa; 98'i 11. sınıfa; 85'i ise 12. sınıfa aittir. 9. sınıfa ait 62 açıklamadan $\% 6,2$ 'si (f 10); 10. sınıfa ait 77 açıklamadan \%3,08'i (f 4); 11. sınıfa ait 98 açıklamadan \%3,92'si (f 4) “kültür” kavramına yönelik vurgular içermektedir. İncelenen 12. sınıfa ait 85 açıklamada ise "kültür" kavramına yönelik herhangi bir vurguya rastlanmamıştır.

Türk Edebiyatı Öğretim Programı'nın $(9,10,11,12)$ “Açıklamalar" kısmında yer alan "kültür" kavramıyla ilgili vurgulardan bazıları şunlardır:

"Kültür alanının (tinsel tabakanın-manevi alanın) dille ve dile göre, dilin imkânlarıyla oluştuğu belirtilir. Dilin bireyin kültürel kimliğini meydana getirdiği ve ifade ettiği vurgulanır." (9. sınıf s. 19)

"Dönemin kültür ve sanat hayatıyla şair arasındaki ilişki açıklanır.” (9. sınıf s. 23) 
"Şiirin okuyucunun kültürüne, anlayışına, zevkine, içinde bulunduğu duruma ve psikolojik hâline göre yeni anlam değerleri kazandığı vurgulanır." (9. sinıf s. 26)

"Metindeki unsurlardan hareketle metnin yazıldığı dönemin sosyal, siyasi ve kültürel hayatının özelliklerini belirler." (9. sınıf s. 30)

"Yazarın, dönemin kültür ve sanat hayatıyla ilişkisi belirlenir."

"Hikâye ve roman metninin, okuyucunun kültürüne, anlayışına, zevkine, içinde bulunduğu duruma ve psikolojik hâline göre yeni anlam değerleri kazandığı vurgulanır.” (9. sınıf s. 33)

"Metnin yazıldığı dönemin sosyal, siyasi ve kültürel hayatının özellikleri metinden hareketle sorgulanır. Yazarın, dönemin kültür ve sanat hayatıyla ilişkisi belirlenir." (9. sınıf s. 36)

"Farklılığın "bakış açısı"ndan kaynaklandığı, bir konuya farklı bakış açılarından yaklaşılabileceği ve bilgi, inanç, düşünce farklılığının, kültürel çevrenin, psikolojik özelliklerin bakış açısını belirlediği vurgulanır." (9. sınıf s. 37)

"Kültür alanlarıyla ilgili farklı çalışma, kavram ve nesnelerin bir tarihi olduğu vurgulanır." (10. sınıf s. 40)

"Türk destanlarının birbiriyle ve diğer kültürlerin destanlarıyla yapı, tema, dil ve anlatım bakımından karşılaştırılması sağlanır." (10. sinif s. 45)

"Bu kazanım işlenirken incelenen şiirden hareketle İslamiyet'in kabulüyle birlikte Türk toplumunda görülen kültür farklılığının açıklanması sağlanır." (10. sınıf s. 49)

"Sade nesrin açık, kısa cümleli olduğu, bir düşünceyi ifade etmek, bir bilgiyi aktarmak üzere kaleme alındı̆̆ı, dinî, tasavvufi, tarihî, kültürel, ilmî, edebî eserlerin bu dille yazıldığı belirtilir." (10. sınıf s. 60)

"Gazete çevresinde kültür ve edebiyat hayatımıza giren öğretici metin türleri açıklanır." (11. sınıf s. 64)

Şiirin kendi döneminin sosyal ve kültürel ortamıyla ilişkisi sorgulanır. (11. sinif s. 73)

"Kendilerini Fecr-i Âtî (geleceğin şafağı) topluluğu olarak adlandıran gençlerin siyasi ve sosyal yönlerden olduğu gibi, kültür ve zevk bakımlarından da bir dayanakları olmadığı belirtilir." (11. sınıf s. 79) 
"Kültür, devlet - vatandaş ilişkisi, gelecek endişesi alanlarında birbirinden farklı önerilerin ileri sürüldüğ̈̈ vurgulanır; bunların hepsinin millî (ulus) devlet ortak paydasında birleştiği belirtilir." (11. sinıf s. 81)

\section{Türk Edebiyatı Ders Kitaplarına (9, 10, 11, 12) Yönelik Bulgular}

Araştırmada değerlendirmeye alınan Türk Edebiyatı ders kitaplarına $(9,10,11,12)$ ve bu kitaplarda yer alan metinlere ilişkin sayısal bilgiler şu şekildedir:

Tablo 4. Değerlendirilen Türk Edebiyatı Ders Kitaplarına $(9,10,11,12)$ İlişkin Sayısal Bilgiler.

\begin{tabular}{|c|c|c|}
\hline $\begin{array}{c}\text { Sinıf } \\
\text { Düzeyi }\end{array}$ & Türk Edebiyatı Ders Kitapları & $\mathbf{f}$ \\
\hline 9. Sinıf & $\begin{array}{l}\text { Millî Eğitim Bakanlığ1 Talim ve Terbiye } \text { Kurulunun } \\
\text { 18.12.2009 tarih ve } 269 \text { sayılı kurul kararı ile } 2010-2011 \\
\text { öğretim yılından başlayarak } 5 \text { (beş) y1l süreyle ders kitab1 } \\
\text { olarak kabul edilen Türk Edebiyatı } 9 \text { ders kitabı }\end{array}$ & 1 \\
\hline 10. Sinıf & $\begin{array}{l}\text { Millî Eğitim Bakanlığı Talim ve Terbiye Kurulunun } \\
\text { 27.07.2011 tarih ve } 96 \text { sayılı kurul kararı ile 2012-20113 } \\
\text { öğretim yılından başlayarak } 5 \text { (beş) yıl süreyle ders kitab1 } \\
\text { olarak kabul edilen Türk Edebiyatı } 10 \text { ders kitabı }\end{array}$ & 1 \\
\hline 11. Sinıf & $\begin{array}{l}\text { Millî Eğitim Bakanlığı Talim ve Terbiye Kurulunun } \\
\text { 08.12.2011 tarih ve } 253 \text { sayılı kurul kararı ile kabul edilmiş, } \\
\text { Destek Hizmetleri Genel Müdürlüğünün 19.03.2012 gün ve } \\
\text { 3398 sayılı yazısı ile ders kitabı olarak kabul edilen Türk }\end{array}$ & 1 \\
\hline 12. Sinıf & $\begin{array}{l}\text { Millî Eğitim Bakanlığı Talim ve Terbiye Kurulunun } \\
\text { 08.11.2011 tarih ve } 193 \text { sayılı kurul kararı ile } 2012-2013 \\
\text { öğretim yılından başlayarak } 5 \text { (beş) y1l süreyle ders kitab1 } \\
\text { olarak kabul edilen Türk Edebiyatı } 12 \text { ders kitabı }\end{array}$ & 1 \\
\hline TOPLAM & & 4 \\
\hline
\end{tabular}

Araştırmada değerlendirmeye alınan değerlendirilen Türk Edebiyatı ders kitaplarında $(9,10,11,12)$ somut olmayan kültürel miras ile ilgili metinlerin sınıf düzeylerine göre dağılımı ise şu şekildedir: 
Tablo 5: Değerlendirilen Türk Edebiyatı Ders Kitaplarında $(9,10,11,12)$ Somut Olmayan Kültürel Miras ile İlgili Metinlerin Sınıf Düzeylerine Göre Dağılımı

\begin{tabular}{cccc}
\hline Sınıf Düzeyi & $\begin{array}{c}\text { Sınıf Düzeylerine Göre } \\
\text { Toplam Metin (f) }\end{array}$ & \multicolumn{2}{c}{$\begin{array}{c}\text { Somut Olmayan Kültürel Mirasa İliş- } \\
\text { kin Metin Sayıları ve Oranları }\end{array}$} \\
\cline { 3 - 4 } 9. Sınıf & 129 & $(\mathrm{f})$ & $\%$ \\
10. Sınıf & 102 & 33 & 42,47 \\
11. Sınıf & 83 & 65 & 66,3 \\
12. Sınıf & 87 & 4 & 3,32 \\
TOPLAM & 401 & 2 & 1,74 \\
\hline
\end{tabular}

Tablo 5'te görüldüğü üzere incelenen Türk edebiyatı ders kitaplarında yer alan toplam 401 metinden 129'u 9. sinıfa; 102'si 10. sınıfa; 83'ü 11. sınıfa; 87'si ise 12. sinıfa aittir. 9. sinıfa ait 129 metinden \%42,47'si (f 33); 10. sinıfa ait 102 metinden \%66,3'ü (f 65); 11. sinıfa ait 83 metinden $\% 3,32$ 'si (f 4 ); 12. sinıfa ait 87 metinden $\% 1,74$ 'ü (f 2) somut olmayan kültürel miras ögeleriyle ilgilidir.

Araştırma kapsamında incelenen ders kitaplarında somut olmayan kültürel miras alanlarıyla ilgili şu ögeler tespit edilmiştir:

Tablo 6. Değerlendirilen Türk Edebiyatı Ders Kitaplarında Somut Olmayan Kültürel Miras Alanlarıyla İlgili Ögelerin Sınıf Düzeylerine Göre Dağılımı.

\begin{tabular}{|c|c|c|c|c|c|c|}
\hline $\begin{array}{l}\text { Sinıf } \\
\text { Düzeyi }\end{array}$ & $\begin{array}{c}\text { Yaşayan } \\
\text { Insan Ha- } \\
\text { zineleri/ } \\
\text { Geleneğin } \\
\text { Ustaları } \\
\end{array}$ & $\begin{array}{c}\text { Sözlü Gele- } \\
\text { nekler ve } \\
\text { Anlatımlar }\end{array}$ & $\begin{array}{c}\text { Gösteri } \\
\text { Sanatları }\end{array}$ & $\begin{array}{l}\text { Toplumsal } \\
\text { Uygulama- } \\
\text { lar, Ritüel- } \\
\text { ler ve Şö- } \\
\text { lenler } \\
\end{array}$ & $\begin{array}{l}\text { Doğa ve } \\
\text { Evrenle } \\
\text { İlgili Uy- } \\
\text { gulama- } \\
\quad \text { lar } \\
\end{array}$ & $\begin{array}{c}\text { El } \\
\text { Sanat- } \\
\text { ları } \\
\text { Gele- } \\
\text { neği } \\
\end{array}$ \\
\hline 9. Sinif & 13 & 18 & - & 1 & - & 1 \\
\hline 10. Sinıf & 13 & 52 & & - & - & - \\
\hline 11. Sinıf & 2 & 1 & 1 & - & - & - \\
\hline 12. Sinıf & - & 2 & - & - & - & - \\
\hline TOPLAM & 28 & 73 & 1 & 1 & - & 1 \\
\hline
\end{tabular}

Tablo 6'dan anlaşıldığı gibi incelenen Türk edebiyatı ders kitaplarında yer alan toplam 401 metinde somut olmayan kültürel miras ögelerinden yaşayan insan hazineleri/geleneğin ustaları ögesi 9. sinıfta $13 ; 10$. sinıfta 13; 11. sinıfta 1 ; sözlü gelenekler ve anlatımlar ögesi 9. sinıfta $18 ; 10$. sinıfta 52; 11. sinıfta $2 ; 12$. sinıfta 2 ; gösteri sanatlarl ögesi 11. sinifta 1; toplumsal uygulamalar, ritüeller ve anlatımlar ögesi 9. sinıfta 1; el sanatları geleneği ögesi 9. sınıfta 1 adet 
olarak belirlenmiștir. Doğa ve evrenle ilgili uygulamalar ögesi ise incelenen hiçbir Türk edebiyatı ders kitabında saptanmamıştır.

9. sınıf Türk edebiyatı ders kitabında somut olmayan kültürel miras ögelerinden yaşayan insan hazineleri/geleneğin ustalar ögesiyle ilgili saptanan vurgular içinde Karacaoğlan (s. 27, 42, 63); Âşık Veysel Şatıroğlu (s. 28); Âşık Şenlik (s. 41); Kâğızmanlı Hıfzı (s. 44); Yunus Emre (s. 46); Erzurumlu Emrah (s. 51); Kuloğlu (s. 61); Âşık (s. 63) gibi ozanlardan verilen örnekler; sözlü gelenekler ve anlatımlar ögesiyle ilgili saptanan vurgular içinde ise hoyrat (s. 22); tekerleme (s. 29); koçaklama (s. 42); türkü (s. 42, 58, 77); ilahi (s. 46); mani (s. 49, 51, 54, ); destan (s. 95, 106); Karagöz (s. 97, 166); masal (s. 121, 138); halk hikâyesi (s. 143); meddah (s. 164) gibi türler yer almaktadır. "Topacın İpi Vardır; Ama" (s. 196) başlıklı metnin toplumsal uygulamalar, ritüeller ve anlatımlar ögesiyle ilgili olduğu saptanmıştır. El sanatları geleneği ögesiyle ilgili olarak ise "Benim yârim, bezden kilim / Dokur Konya'da, Konya'da" (s. 32) dizelerinde geçen "bezden kilim" vurgusuna rastlanmıştır.

10. sınıf Türk Edebiyatı ders kitabında somut olmayan kültürel miras ögelerinden yaşayan insan hazineleri/geleneğin ustalart ögesiyle ilgili saptanan vurgular içinde Pir Sultan Abdal (s.25); Seyranî (s. 94); Mevlâna (s. 109); Nasreddin Hoca (s. 117); Kaygusuz Abdal (s. 115); Âşık Veysel Şatıroğlu (s. 157); Âşık Ömer (s. 159); Karacaoğlan (s.160); Kayıkçı Kul Mustafa (s. 161); Gevheri (s. 161); Köroğlu (s. 125, 161, 166); Dertli (s. 161); Kuloğlu (s. 161); Âş1k (s. 162); Dertli (s. 163) gibi şahıslardan verilen örnekler; sözlü gelenekler ve anlatımlar ögesiyle ilgili saptanan vurgular içinde ise efsane (s. 18, 28, 32); destan (s. 27, 42, 95, 99, 106); sagu (s. 36); koşuk (s. 38, 93); ilahi (s. 87); nefes (s. 89); fikra (s. 117), mani (s. 125, 149, 155); türkü (s. 151, 153, 154, 166); ninni (s. 153); halk hikâyesi (s. 168); Karagöz (s. 185); Meddah (s. 194); orta oyunu (s. 197) gibi türler yer almaktadir.

11. sınıf Türk Edebiyatı ders kitabında somut olmayan kültürel miras ögelerinden yaşayan insan hazineleri/geleneğin ustalar ögesiyle ilgili olarak Âşık Veysel Şatıroğlu (s. 37); Nasreddin Hoca (s. 166); sözlü gelenekler ve anlatımlar ögesiyle ilgili fikra (s. 166) vurgularına rastlanmıştır. "Köy Düğünü” (s. 104) başlıklı metnin ise toplumsal uygulamalar, ritüeller ve anlatımlar ögesiyle ilgili olduğu saptanmıştır. 
12. sınıf Türk Edebiyatı ders kitabında somut olmayan kültürel miras ögelerinden sözlü gelenekler ve anlatımlar ögesiyle ilgili vurgular içeren "Baldaki Tuz" (s. 135) başlıklı bir metin saptanmıştır. Metinde Âşıłk Veysel'le ilgili vurgular yer almaktadır.

\section{Sonuç ve Tartışma}

$\mathrm{Bu}$ bölümde araştırmanın bulgularına dayalı olarak ulaşılan sonuçlarla getirilebilecek önerilere yer verilmiştir.

Araştırmada ilk önce Türk Edebiyatı Öğretim Programındaki kazanımlarda, etkinlik örneklerinde ve açıklamalarda; daha sonra Türk Edebiyatı ders kitaplarında yer alan metinlerde Somut Olmayan Kültürel Mirasın Korunması Sözleşmesine göre halk bilimi kadroları ile ilgili ögeler (yaşayan insan hazineleri / geleneğin ustaları; sözlü gelenekler ve anlatımlar; gösteri sanatları; toplumsal uygulamalar, ritüeller ve şölenler; el sanatları geleneği) incelenmiştir.

İncelemeye tabi tutulan Türk Edebiyatı Öğretim Programında $(9,10,11,12)$ yer alan toplam 649 kazanımdan 123'ü 9. sinıfa; 152'si 10. sinıfa; 199'u 11. sinıfa; 175'i ise 12. sinıfa aittir. 9. sinıfa ait 123 kazanımdan \%4,92'si (f 4); 10. sinıfa ait 152 kazanımdan \%13,68'i (f 9); 11. sınıfa ait 199 kazanımdan \%11,94'ü (f 6); 12. sınıfa ait 175 kazanımdan \%3,5'i (f 2) "kültür" kavramına yönelik vurgular içermektedir.

Değerlendirilen Türk Edebiyatı Öğretim Programında (9, 10, 11, 12) yer alan toplam 269 etkinlik örneğinden 70'i 9. sınıfa; 70'i 10. sinıfa; 79'u 11. sınıfa; 50'si ise 12. sinıfa aittir. 9. sinıfa ait 70 etkinlik örneğinden \%2, 1'i (f 3); 10. sinıfa ait 70 etkinlik örneğinden \%2,1'i (f 3); 11. sinıfa ait 79 etkinlik örneğinden \%1,58'i (f 2) "kültür" kavramına yönelik vurgular içermektedir. İncelenen 12. sınıfa ait 50 etkinlik örneğinde ise "kültür" kavramına yönelik herhangi bir vurgu saptanmamıştır.

Araştırma kapsamında incelenen Türk Edebiyatı Öğretim Programında $(9,10,11,12)$ yer alan toplam 322 açıklamadan 62'si 9. sınıfa; 77'si 10. sınıfa; 98'i 11. sinıfa; 85'i ise 12. sınıfa aittir. 9. sınıfa ait 62 açıklamadan \%6,2'si (f 10); 10. sınıfa ait 77 açıklamadan $\% 3,08$ 'i (f 4); 11. sınıfa ait 98 açıklamadan \%3,92'si (f 4) "kültür" kavramına yönelik vurgular içermektedir. İncelenen 12. sınıfa ait 85 
açıklamada ise "kültür" kavramına yönelik herhangi bir vurguya rastlanmamıştır.

İncelenen Türk Edebiyatı ders kitaplarında $(9,10,11,12)$ yer alan toplam 401 metinden 129'u 9. sinıfa; 102'si 10. sinıfa; 83'ü 11. sinıfa; 87'si ise 12. sinıfa aittir. 9. sinıfa ait 129 metinden \%42,47'si (f 33); 10. sinıfa ait 102 metinden \%66,3'ü (f 65); 11. sinıfa ait 83 metinden \%3,32'si (f 4); 12. sinıfa ait 87 metinden \%1,74'ü (f 2) somut olmayan kültürel miras ögeleriyle ilgilidir.

Türk edebiyatı ders kitaplarında yer alan toplam 401 metinde somut olmayan kültürel miras ögelerinden yaşayan insan hazineleri/geleneğin ustalar ögesi 9. sinıfta $13 ; 10$. sinifta $13 ; 11$. sinifta 1 ; sözlü gelenekler ve anlatımlar ögesi 9. sinıfta 18; 10. sinıfta 52; 11 . sinıfta 2; 12. sinıfta 2; gösteri sanatları ögesi 11. sinıfta 1; toplumsal uygulamalar, ritüeller ve anlatımlar ögesi 9. sınıfta 1; el sanatları geleneği ögesi 9. sınıfta 1 adet olarak belirlenmiştir. Doğa ve evrenle ilgili uygulamalar ögesi ise incelenen hiçbir Türk edebiyatı ders kitabında saptanmamıştır.

Araştırma sonuçlarına somut olmayan kültürel mirası koruma bakımından edebiyat eğitiminin önemine yönelik şu öneriler getirilebilir:

1. Türk Edebiyatı Öğretim Programında somut olmayan kültürel mirasa yönelik ifadeler kültür aktarımı ve kalıcılığı bakımından yeniden gözden geçirilmelidir.

2. Türk Edebiyatı ders kitaplarında somut olmayan kültür değerlerine yönelik bilinç ve farkındalığı arttıracak, düzeye uygun etkinliklere yer verilmelidir.

3. Türk Edebiyatı ders kitapları somut olmayan kültür değerleriyle ilgili daha fazla ifadeler içeren metinlerle zenginleştirilmelidir.

4. Oyunların çocuğun kişilik gelişimi yanında, sosyal, kültürel ve dil geliş̧imine da katkı sağladığı bilinmektedir. $\mathrm{Bu}$ sebeple, Türk Edebiyatı ders kitaplarında geleneksel çocuk oyunlarını cazip hale getirecek, çocuklarda bu oyunlara ilgi uyandıracak metinlere yer verilmelidir.

5. Kültürün aktarımında öğretmenlerin bitmez tükenmez görevlerinin olduğu gerçeği yadsınamaz. Türk Edebiyatı Öğretim Programında öğretmenlerin faydalanabileceği somut olmayan kültürel miras öğretimi ile ilgili uygulamaya yönelik etkinlik örnekleri sunulmalıdır. 
Vafa Şavaşkan / Ë̈ Ĕgitim Fakültesi Dergisi, 18-2 (2016), 1302-1323

\section{Kaynaklar}

Akhan, N. E. (2014). Sosyal Bilgiler Derslerinde Somut Olmayan Kültürel Miras Öğretimi. International Online Journal of Educational Sciences, 6 (3), 722736

Çengelci, Tuba. (2012). Sosyal Bilgiler Öğretim Programında Somut Olmayan Kültürel Mirasın Yeri. Uludăg Üniversitesi Eğitim Fakültesi Dergisi, 25 (1), 185-203

Geçmen, C. ve Bursalıoğlu, (2013).Y. Türk Edebiyatı 9. Ankara: Firat Yayıncılık.

Kavcar, C. (1995). Edebiyat ve Eğitim. Ankara: Engin Yayınevi.

Kolaç, E. (2009). Somut Olmayan Kültürel Mirası Koruma, Bilinç ve Duyarlılık Oluşturmada Türkçe Eğitiminin Önemi. Milli Folklor 82, 19-31.

Komisyon, (2012). Türk Edebiyatı 11. Ankara: MEB Yayınları,

MEB (2011). Ortaögretim Türk Edebiyatı 9, 10, 11 ve 12. Sinıflar Öğretim Programl. Ankara: Millı̂ Eğitim Bakanlığı, 2011.

Miles M.B. \& Huberman A.M. (1994). Qualitative Data Analysis: An Expanded Sourcebook 2nd Edition. SAGE Publications, Calif.

Oğuz, M. Ö. (2009). Somut olmayan kültürel miras ve kültürel ifade çeşitliliği. Milli Folklor, 21(82), 6-12.

Oğuz, M. Ö. (2013). Somut Olmayan Kültürel Miras Nedir? (2.bsk.)Ankara: Geleneksel Yayınları

Solak, A. Kuramdan Uygulamaya Edebiyat Çalışmaları. Ankara: Anı Yayınları, 2014.

Şimşek, F. I. (2008). "Fakelore" Kavramı ve Nasreddin Hoca" Millî Folklor, 20, 79.

TDK. (2005). Türkçe Sözlük. Ankara: Türk Dil Kurumu,

Yeşilbursa, C. (2011). Sosyal bilgilerde miras eğitiminin öğrencilerin somut kültürel mirasa karşı tutumlarına ve akademik başarılarına etkisi. Yayımlanmamış doktora tezi. Gazi Üniversitesi Eğitim Bilimleri Enstitüsü, Ankara.

Yıldırım, A. ve Şimşek, H. (2011). Nitel Araştırma Yöntemleri. (8. Baskı). Ankara: Seçkin.

Yıldırım, C. ve Ova, A. A. (2013). Türk Edebiyatı 12. Ankara: Lider Yayıncılık.

Yılmaz, O. (2014). Türkiye ve Kazakistan'da Okutulan Türkçe Öğretmenliği Lisans Programlarının Karşılaştırılması Üzerine Bir Çalışma. Cilt-Sayı: 16-2

Yücekaya, K. (2013). Türk Edebiyatı 10. Ankara: Bir-Yay Yayınevi. 
Vafa Şavaşkan / Ë̈ Eğitim Fakültesi Dergisi, 18-2 (2016), 1302-1323

\section{Purpose}

\section{Extended Summary}

Thus, Turkish Literature Teaching Curriculum and Turkish Literature textbooks should include items facilitating the transmission of the intangible cultural heritage of Turkish culture. The aim of the present study is to examine whether 9th, 10th, 11th, and 12th grade Turkish Literature Teaching Curriculum and the textbooks help the transmission of the intangible cultural heritage. To achieve this aim, related items (living human treasures / masters of the tradition; oral traditions and expressions, performing arts; social practices, rituals and festivals; crafts) of folklore based on the Intangible Cultural Heritage Aggreement in the objectives of Turkish Literature Curriculum, activities and explanations, and texts in Turkish Literature textbooks were investigated.

\section{Method}

The present study which tries to determine if Turkish Literature Curriculum and Turkish Literature text books can achieve their objectives in terms of protecting intangible cultural heritage is a qualitative research that was carried out through document evaluation. In order to specify the methodological bases for the study, firstly a literature review was conducted in the field of intangible cultural heritage. Then, the objectives, sample activities and explanations in the Turkish Literature Curriculum and the texts in the Turkish Literature textbooks were examined, and the findings were presented with frequency tables. In addition, direct references were made from the investigated data when necessary.

For the reliability assessment, Miles and Huberman (1994) reliability formula was used. In addition, another expert was asked for to evaluate the objectives, sample activities and explanations in the Turkish Literature Curriculum and the texts in the Turkish Literature textbooks in terms of intangible cultural heritage. While evaluating the data, both the researcher and the expert paid special attention to the fact that all the samples that were detected should be relevant to the fields of intangible cultural heritage (living human treasures / masters of the tradition; oral traditions and expressions, performing arts; social practices, rituals and festivals; practices concerning the nature and universe, and the traditional handicrafts). The basic criterion is to determine at least one item which is relevant to the fields of intangible cultural heritage in the sample activities, objectives and texts that were examined. It was decided that the reliability process was to be ended when the researcher and the expert came to an agreement. In the next level, the reliability assessment was done by comparing the results. At the end of the assessment, the value of $p=0,82$ was found. It is accepted as reliable if the reliability assessment is above 70\% (Miles \&Huberman 1994). Thus, the findings that were obtained as a result of the study are considered to be reliable. These findings that passed through such a reliability process were presented with frequency tables and also direct references were included when necessary. 
Vafa Şavaşkan / Ë̈ Eğitim Fakültesi Dergisi, 18-2 (2016), 1302-1323

\section{Results}

The total number of the objectives that was evaluated for this study from the Turkish Literature Curriculum is 649 and 123 of these objectives belong to the 9th grade, 152 of them belong to the 10th grade, 199 objectives are related to the 11 th grade and finally 175 of these objectives belong to the 12th grade. Furthermore, $4,92 \%$ (f4) of the 123 objectives for the 9th grade, $13,68 \%$ (f9) of the 152 objectives for the 10th grade, $11,94 \%$ (f 6) of the 199 objectives for the 11th grade, and 3,5\% (f2) of the 175 objectives for the 12th grade have references to the concept of "culture".

For the evaluation, 269 activity samples were taken from the Turkish Literature Curriculum, 70 of which belong to the 9th grade, 70 to the 10th grade, 79 to the 11 th grade, and 50 to the 12 th grade. In addition, $2,1 \%$ (f3) of the 70 activity samples from the 9 th grade, $2,1 \%$ (f3) of the 70 activity samples from the 10 th grade, and $1,58 \%$ (f2) of the 79 activity samples from the 11th grade have references to the concept of "culture". There weren't any references to the concept of "culture" in the 50 activities that were examined at the 12 th grade.

Of the total 322 explanations evaluated in this study from the Turkish Literature Curriculum, 62 explanations belong to the 9th grade, 77 belong to the 10th grade, 98 belong to the 11 th grade and 85 belong to the 12 th grade. $6,2 \%$ (f10) of the 62 explanations from the 9 th grade; $3,08 \%$ (f 4 ) of the 77 explanations from the 10th grade; and 3,92\% (f4) of the 98 explanations from the 11th grade have references to the concept of "culture". There weren't any references to the concept of "culture" in the 85 explanations that were examined at the 12 th grade.

As for the 401 texts from the Turkish Literature textbooks that were examined for this study, 129 texts belong to the 9th grade, 102 texts belong to the 10 th grade, 83 texts belong to the 11 th grade, and 87 texts belong to the 12 th grade. $42,47 \%$ (f33) of the 129 texts from the 9 th grade; $66,3 \%$ (f 65 ) of the 102 texts from the 10th grade; $3,32 \%$ (f 4 ) of the 83 texts from the 11 th grade; and 1,74\% (f 2) of the 87 texts from the 12 th grade are related to the elements of intangible cultural heritage.

The distribution of the intangible cultural heritage elements in the 401 texts from the Turkish Literature textbooks is as follows: living human treasures / masters of the tradition have 13 references at the 9th grade, 13 references at the 10th grade, and 1 reference at the 11th grade; the element of oral traditions and expressions has 18 references at the 9th grade; 52 references at the 10th grade; 2 references at the 11 th grade; and 2 references at the 12th grade; the element of performing arts has 1 reference at the 11th grade; social practices, rituals and festivals have 1 reference at the 9th grade; the element of traditional handicrafts has 1 reference at the 9th grade. The element of practices concerning the nature and universe hasn't been observed in any of the Turkish Literature textbooks that were examined. 
Vafa Şavaşkan / Ë̈ Eğitim Fakültesi Dergisi, 18-2 (2016), 1302-1323

\section{Discussion and Conclusion}

As a result of the present study, it can be said that references to the intangible cultural heritage in the Turkish Literature Curriculum should be revised in terms of culture transmission and retention. Turkish Literature textbooks should include activities based on levels to increase the students' awareness of intangible cultural heritage. The content of these textbooks should be enriched through involving texts which have more expressions related to the intangible cultural values.

It is generally accepted that games contribute to the children's social, cultural and linguistic development as well as their personality development. Thus, Turkish Literature textbooks should include texts which can make traditional children games attractive and can make children interested in such games.

It cannot be denied that teachers have infinite duties in the process of culture transmission. In order to facilitate that, teachers should be provided with practical sample activities related to the intangible cultural heritage instruction. 